\title{
Does remembering emotional items impair recall of same-emotion items?
}

\author{
Jo Ann G. Sison ANd Mara Mather \\ University of California, Santa Cruz, California
}

\begin{abstract}
In the part-set cuing effect, cuing a subset of previously studied items impairs recall of the remaining noncued items. This experiment reveals that cuing participants with previously-studied emotional pictures (e.g., fearevoking pictures of people) can impair recall of pictures involving the same emotion but different content (e.g., fear-evoking pictures of animals). This indicates that new events can be organized in memory using emotion as a grouping function to create associations. However, whether new information is organized in memory along emotional or nonemotional lines appears to be a flexible process that depends on people's current focus. Mentioning in the instructions that the pictures were either amusement- or fear-related led to memory impairment for pictures with the same emotion as cued pictures, whereas mentioning that the pictures depicted either animals or people led to memory impairment for pictures with the same type of actor.
\end{abstract}

Contrary to common belief, recalling something to someone does not necessarily facilitate that person's retrieval of related memories. In fact, reminding someone that they have studied the word "banana" on a word list can actually make it harder for them to recall that they have also studied the word "pear." Many studies using different methods have demonstrated similar effects: For example, in the basic part-set cuing paradigm, re-presenting people with a subset of items from a studied list can impair memory for the remaining items.

The part-set cuing effect has been demonstrated across a variety of test and stimuli types. It has been observed in episodic memory tasks where participants learn a list of items for the first time (Slamecka, 1968), as well as in semantic memory tasks in which participants recall lists from their long-term memory store (e.g., producing a list of U.S. states; Brown, 1968). Part-set effects are typically studied using free-recall tests, but the effect has also been observed using implicit memory tests (Peynircioğlu \& Moro, 1995) and recognition memory tests (Neely, Schmidt, \& Roediger, 1983).

In this study, we investigated whether part-set cuing effects are obtained with stimuli that elicit emotions, such as pictures of emotional scenes. Finding the part-set cuing effect with emotion-eliciting materials would support the idea that emotions can act as an organizing principle in memory (e.g., Bower, 1981; Niedenthal, Halberstadt, \& Innes-Ker, 1999; Schulkind \& Woldorf, 2005). According to Bower's network theory of emotion, each emotion is represented by a node in memory that integrates verbal labels, expressive behaviors, autonomic responses, evoked appraisals, and, finally, episodic events related to the emotion. Bower's theory assumes that as long as a node in an emotion-based network of information is activated above threshold, activation of other nodes along the network spreads automatically. Consistent with this idea that emotions are organized in memory in ways that resemble information from other categories, the enhancement seen in memory for valenced rather than neutral words and pictures depends in part on their semantic relatedness and their being from the same category (Phelps et al., 1998; Talmi, Luk, McGarry, \& Moscovitch, 2007; Talmi \& Moscovitch, 2004).

Mood-congruent memory, in which material consistent with the participant's emotional state is better learned or retrieved than emotionally inconsistent material (Blaney, 1986), also suggests that information is organized along emotional lines. Most mood-based memory effects have been found with experimental paradigms that use moodinduction techniques such as hypnosis and Velten mood induction (Blaney, 1986; Singer \& Salovey, 1988). However, these induction procedures have been criticized for a number of reasons (e.g., Hasher, Rose, Zacks, Sanft, \& Doren, 1985). Among other problems, artificially created moods are often more intense than typically occurring moods, and they have the side effect of focusing participants on the emotional aspects of stimuli, which may create inadvertent demand characteristics for participants to retrieve emotional materials.

In contrast, when naturally occurring mood states are studied, mood-congruent effects are often attenuated. Hartig, Nyberg, Nilsson, and Garling (1999) found no mood-congruent effects when using naturalistic mood inductions (showing pictures of calm landscapes rather than of urban environments), and a study by Hasher et al. (1985) involving normal and depressed college students

M. Mather, mather@ucsc.edu 
found no mood-congruent effects for naturally occurring moods. Experiments using natural mood states have even yielded cases of mood-incongruent memory, such as in Parrott and Sabini (1990), in which participants retrieved autobiographical memories that contradicted the mood state. The effect of experimenter-induced mood states versus naturally occurring mood states on memory is called further into question by Eich and Macaulay's (2000) finding that simulating a mood state in the absence of an actual mood not only produces mood-congruent memory effects, but also a different pattern of results compared to those found in actual mood states. The lack of consistency in the literature suggests that effects of mood on memory are moderated by the salience of the emotion state; the effects are present if participants are highly aware of the emotionality of the situation (as may happen during contrived mood-induction procedures), but the effects disappear if the mood is naturally occurring and therefore not as salient.

To help explain these inconsistencies, we point to Niedenthal et al.'s (1999) proposal that the organization of items into emotional categories is a specific case of ad hoc categorization (Barsalou, 1983), in which current goals direct the classification of objects. For example, cabinet could be classified under the taxonomic grouping furniture, but it could also be classified under the ad hoc grouping things to sell at a garage sale, depending on goals of the moment. Similarly, an object in the environment might be categorized according to its emotional characteristics, if such categorization best suited the particular situation. From this perspective, an emotion-based categorization process should be flexible to accommodate changing goals.

In our study, we examined whether the organization of information along emotional lines is an automatic process that always occurs in response to emotionally evocative stimuli, or whether it depends on what category is the most salient organizational scheme at the time of encoding. In our study, we showed participants emotional pictures using methods similar to previous part-set cuing paradigms to see whether we could find evidence for the emotional organization of new nonautobiographical information in memory. Like most real-world events that elicit emotions, the emotional pictures could also be categorized along nonemotional lines - in this case, people versus animals - as well as along emotional lines - in this case, fear versus amusement. There were four randomly intermixed subsets of pictures shown in the initial slide show: (1) fear-evoking pictures of people, (2) amusing pictures of people, (3) fear-evoking pictures of animals, and (4) amusing pictures of animals.

Participants in cue conditions were given word cues to retrieve each picture from one of these subsets. The question of interest was how many pictures would later be recalled from the same-emotion (but different-actortype) set and the same-actor-type (but different-emotion) set, versus the no-match set. If memories are indeed associated with one another via emotion-based associations, prompting the retrieval of pictures that elicit an emotional response should impair recall of the remaining noncued items that elicit the same emotional response; this emo- tion effect should occur even when the cued pictures depict people and the target nonpracticed pictures depict animals. On the other hand, if emotion does not act as an organizing principle, reviewing pictures for one emotional type should not affect recall of noncued same-emotion items more than other noncued items.

To address our question of whether emotional categorizations always occur or whether such categorization is flexible, we mentioned to half the participants that the picture set involved fear and amusement and mentioned to the other half that the picture set involved people and animals. If emotional categorization occurs whenever stimuli are associated with a particular emotion, it should occur in both conditions.

\section{METHOD}

\section{Participants}

One hundred forty-nine undergraduates from the University of California at Santa Cruz participated in the experiment for partial credit in an introductory psychology class.

\section{Materials}

Four amusing animal pictures, four amusing people pictures, four fear-inducing animal pictures, and four fear-inducing people pictures were chosen from the International Affective Picture Set (IAPS; Lang, Bradley, \& Cuthbert, 1999). The animal and people pictures were selected so that there were no recurrences of similar pictures (e.g., multiple pictures of dogs). In order to find pictures that induced the specific emotions of amusement or fear, we used the emotion categorizations for the IAPS pictures (see Table 1 for the picture list), based on a large sample of raters from Mikels et al. (2005).

\section{Procedure}

Participants were assigned to either a no-cue (control) condition or to one of four cue conditions in which participants were reminded of all the pictures in one of the four categories (e.g., all the amusing animal pictures). The pictures were presented using PsyScope software on a Macintosh computer. In the actor-salient condition, a sentence in the instructions stated that participants would view pictures of animals or people, in the emotion-salient condition the sentence stated that participants would view pictures depicting amusement or fear. All participants then viewed a randomized slideshow of the 16 pictures. Because the picture set was relatively small, to avoid recall at ceiling levels, each picture was presented for a duration of $1 \mathrm{sec}$. After the slideshow, participants did an unrelated filler task for $5 \mathrm{~min}$.

Participants in the cue conditions were then cued to retrieve all four pictures of a particular item type (e.g., all the amusing people pictures) in the following sequence for each cued picture: (1) A word

Table 1

Picture Sets and Their Corresponding Numbers From the International Affective Picture System

\begin{tabular}{lclc}
\hline Content & Number & \multicolumn{1}{c}{ Content } & Number \\
\hline \multicolumn{4}{c}{ Amusing Animals and Amusing People } \\
Kittens & 1463 & Clowns & \\
Hippo & 1810 & Children & 2092 \\
Monkeys & 1811 & Kiss & 2344 \\
Porpoise & 1920 & Balloons & 2791 \\
\multicolumn{5}{c}{} \\
Snake & Fear-Inducing Animals and Fear-Inducing People \\
Dog & 1022 & Dental exam \\
Bear & 1301 & Soldier & 3280 \\
Shark & 1321 & Dead body & 6212 \\
\hline
\end{tabular}


phrase corresponding to one of the pictures was shown on the screen (e.g., "clowns") and instructions on the computer screen asked participants to visualize the picture that matched the phrase and to press the space bar after visualizing the corresponding picture; (2) after the space bar was pressed, the corresponding picture appeared; (3) participants were asked to give a rating from 1 to 7 on how easy it was to visualize the picture. Control condition participants did word completion tasks in place of the cue procedure.

Next, after a 10-min interval, all participants were given a written free-recall test in which they were asked to list as many of the pictures as they remembered from the slideshow.

\section{RESULTS}

Unless there was no match, two coders identified the picture to which each recalled item corresponded. They agreed for $99.2 \%$ of recalled items, and discrepancies were resolved by discussion. Thirty-nine $(2.9 \%)$ of the recalled items (e.g., "people," "lion") could not be matched with any picture and so were not included in our analyses.

In the following analyses, we report $\eta_{\mathrm{p}}^{2}$ as a measure of effect size. We used $95 \%$ confidence intervals to compare means. First, we examined recall in the control condition in which participants were not reminded of any of the pictures, using a 2 (category mentioned: actor, emotion) $\times 4$ (picture category: amusing animal, amusing people, fear-inducing animal, fear-inducing people) ANOVA for the number of pictures recalled (see Table 2 for means). There was a marginally significant effect of picture category $\left[F(3,84)=2.47, p=.07, \eta_{\mathrm{p}}^{2}=.08\right]$. As shown in Table 2, the pictures in the four categories varied in how likely they were to be recalled, with the least recall for fear-inducing animal pictures. However, there was no significant main effect of the category structure mentioned in the instructions $\left[F(1,28)=1.08, p>.3, \eta_{\mathrm{p}}^{2}=.04\right]$ and no significant interaction of the two factors $[F(3,84)=0.34$, $\left.p>.7, \eta_{\mathrm{p}}^{2}=.01\right]$, indicating that mentioning emotion or actor categories in the instructions did not in itself significantly influence which pictures were recalled.

Next, we examined the data from the four cue conditions, our main focus of interest. In these analyses, we categorized each item recalled as cued, emotion match, actor match, or no match (see Table 3 for means). For instance, for participants in the fear-inducing animal cue condition, the four fear-inducing animal pictures were "cued," the four fear-inducing people pictures were "emotion match," the four amusing animal pictures were "actor match," and the four amusing people pictures were "no match." The av- erage scores for each of these categories are shown in Figure 1 and were analyzed using a 2 (category mentioned: actor, emotion) $\times 4$ (recall type: cued, cued-emotion, cued-actor, noncued) $\times 4$ (cue type: amusing animal, amusing people, fear-inducing animal, fear-inducing people) ANOVA. Not surprisingly, there was a significant effect of recall type $\left[F(3,333)=101.92, p<.001, \eta_{\mathrm{p}}^{2}=\right.$ $.48]$, as participants tended to recall nearly all of the four cued pictures $(M=3.59 \pm .11)$ but fewer of the emotionmatch $(M=1.80 \pm .18)$, actor-match $(M=1.69 \pm .18)$, or no-match $(M=1.96 \pm .20)$ pictures.

Overall recall did not differ significantly among those in the actor-mentioned versus emotion-mentioned conditions $\left[F(1,111)=0.03, p>.8, \eta_{\mathrm{p}}^{2}=.00\right]$. However, the category mentioned led to different patterns of recall for the two instruction conditions, as reflected (see Figure 1) in an interaction of category mentioned and recall type $\left[F(3,333)=3.84, p=.01, \eta_{\mathrm{p}}^{2}=.03\right]$. Of particular interest is whether participants showed impairment for items from the same emotion or actor category as their cued items. In the actor-salient condition, participants showed impairment in memory for actor-match items $(M=1.51 \pm .27)$, compared with recall of the no-match items $(M=1.86 \pm$ .29), but no impairment in memory for emotion-match pictures $(M=2.00 \pm .26)$. In contrast, in the emotionsalient condition, participants showed impairment in memory for emotion-match items $(M=1.60 \pm .26)$ relative to no-match items $(M=2.07 \pm .29)$, but no significant impairment for actor-match items $(M=1.86 \pm .26)$. These results suggest that there was impairment for items from the same category as the cued items, but only when participants were oriented to use that category structure when encoding the pictures. There were no significant effects of cue type, indicating that the pattern of memory impairment was similar in the different cue conditions.

To directly test whether there was impairment for noncued items in the mentioned category relative to the nomatch items, we conducted an ANOVA that compared recall of noncued items that matched both the category mentioned in the instructions and one of the categories of the cued pictures (bars B or C in Figure 1, depending on the participants' condition) to recall of no-match items (bars E or F) as a within-subjects factor. The ANOVA included cue type (amusing animal, amusing people, fearinducing animal, fear-inducing people) and category mentioned (actor, emotion) as between-subjects factors. As expected, recall was significantly worse for noncued

Table 2

Number of Pictures Recalled From Each Category (With Standard Errors) in the Control (No-Cue) Condition

\begin{tabular}{llllll}
\hline & \multicolumn{4}{c}{ Instruction Condition } \\
\cline { 2 - 3 } \cline { 5 - 6 } & \multicolumn{2}{c}{ Actor Salient } & & Emotion Salient \\
\cline { 2 - 3 } \cline { 5 - 6 } & No. of Pictures & $S E$ & & No. of Pictures & $S E$ \\
\hline Recalled Picture Type & & & & & \\
Amusing animal picture recall & 2.07 & .23 & & 1.87 & .23 \\
Amusing people picture recall & 2.27 & .26 & & 2.13 & .26 \\
Fear animal picture recall & 1.80 & .27 & & 1.33 & .27 \\
Fear people picture recall & 2.00 & .23 & & 2.00 & .23 \\
\hline
\end{tabular}


Table 3

Number of Pictures Recalled in Cued and Noncued Categories (With Standard Errors) for Actor-Salient and Emotion-Salient Instruction Conditions

\begin{tabular}{|c|c|c|c|c|}
\hline \multirow[b]{3}{*}{ Cued Picture Type Recalled } & \multicolumn{4}{|c|}{ Instruction Condition } \\
\hline & \multicolumn{2}{|c|}{ Actor Salient } & \multicolumn{2}{|c|}{ Emotion Salient } \\
\hline & No. of Pictures & $S E$ & No. of Pictures & $S E$ \\
\hline \multicolumn{5}{|l|}{ Cued Category } \\
\hline Amusing animals & 3.77 & .20 & 3.50 & .18 \\
\hline Amusing people & 3.64 & .18 & 3.75 & .18 \\
\hline Fear-inducing animals & 3.50 & .22 & 3.20 & .19 \\
\hline Fear-inducing people & 3.64 & .18 & 3.40 & .19 \\
\hline \multicolumn{5}{|l|}{ Emotion Match } \\
\hline Amusing animals & 2.33 & .32 & 1.92 & .27 \\
\hline Amusing people & 1.82 & .29 & 1.58 & .27 \\
\hline Fear-inducing animals & 2.13 & .34 & 1.90 & .30 \\
\hline Fear-inducing people & 2.00 & .29 & 1.70 & .30 \\
\hline \multicolumn{5}{|l|}{ Actor Match } \\
\hline Amusing animals & 1.56 & .28 & 2.67 & .24 \\
\hline Amusing people & 2.00 & .25 & 1.83 & .24 \\
\hline Fear-inducing animals & 1.75 & .29 & 1.80 & .26 \\
\hline Fear-inducing people & 1.72 & .25 & 2.30 & .26 \\
\hline \multicolumn{5}{|l|}{ No Match } \\
\hline Amusing animals & 2.00 & .30 & 2.33 & .26 \\
\hline Amusing people & 2.46 & .28 & 2.33 & .26 \\
\hline Fear-inducing animals & 2.75 & .32 & 2.30 & .29 \\
\hline Fear-inducing people & 1.82 & .28 & 2.10 & .29 \\
\hline
\end{tabular}

Notes-For each type of item recalled (e.g., "emotion match") the eight means are from the eight different subgroups of participants in different cue and instruction conditions. The maximum recall for each item type is 4 . The left-hand column indicates which pictures were cued in the retrieval-practice phase.

items from the mentioned category $(M=1.56 \pm .18)$ than for no-match items $(M=1.96 \pm .20)[F(1,111)=8.56$, $\left.p<.01, \eta_{\mathrm{p}}^{2}=.07\right]$. There were no other significant effects, indicating that this impairment was similar in the emotion- and the actor-salient conditions.

In contrast, using the same between-subjects factors in an ANOVA comparing recall of items that did not match the category mentioned by the instructions but did match one of the categories of the cued pictures (bars A or D in Figure 1) to recall of no-match items (bars E or F) revealed no significant effects (all $p>.2$ ). Thus, impairment did not occur for either emotion-match or actor-match noncued items unless the relevant category had been mentioned in the instructions.

\section{DISCUSSION}

This study reveals two interesting new findings. First, being cued to retrieve information that elicits a particular emotion (e.g., fear-evoking animal pictures) can impair memory for other information that elicits the same emotion, even if that information is otherwise from a different category (e.g., fear-evoking people pictures). This recall impairment for items according to emotional as well as nonemotional categorization indicates that emotion can function as a grouping principle, even when the stimuli are not semantically related other than through the emotion they elicit (Talmi \& Moscovitch, 2004). This finding is consistent with Bower's (1981) theory that there is an associative network of emotion categories that coexists with other forms of categorical knowledge and schemata; it also extends recent findings of emotional organization in autobiographical memories (Barnier, Hung, \& Conway, 2004; Schulkind \& Woldorf, 2005) to more recent, nonautobiographical information in memory.

The second main finding in this study is that the categorization of the pictures as emotional (fear vs. amusement) or nonemotional (people vs. animals) depended on participants' expectations of what they were going to see. Our findings are consistent with the theoretical notion that whether or not emotion is used to organize new information depends on the context: If there is no cue to categorize information along emotional lines, emotion-based categorization does not necessarily occur.

This result highlights the adaptable nature of emotionbased categorization, an idea supported by Barrett's (2006) proposal that the experience of emotion itself is essentially a categorization task that depends in part on context and learned information about emotion experience. The emotion concepts that form the basis of this categorization are a collection of embodied situated conceptualizations (Barsalou, 1999) that are not static representations but are flexible and context dependent.

An interesting question for future research is the extent of the flexibility of the emotional categorizations that lead to facilitation or impairment for items from the same category in memory. Given our findings that similar effects occurred in the emotion-salient and the actor-salient conditions, and that both emotion-based and actor-based part-set cuing effects were dependent on the categorical 


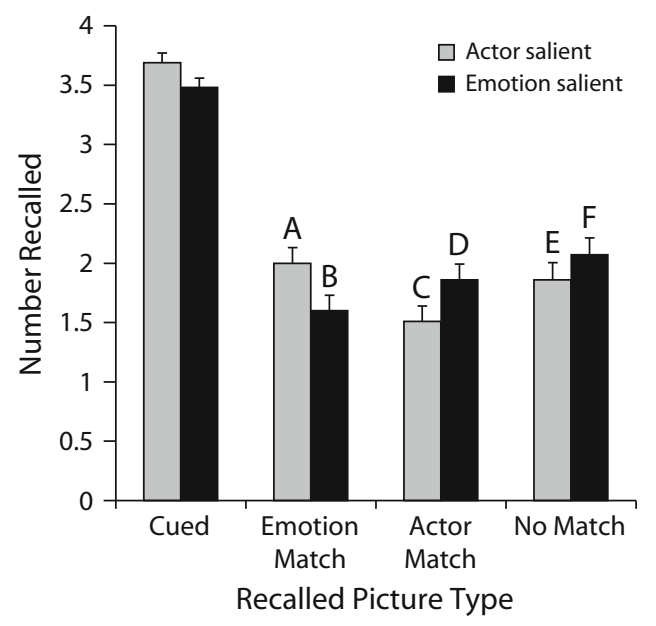

Figure 1. Average number of pictures recalled as a function of the type of match with the cued pictures and whether the instructions made the emotion type or actor type salient. The letters $\mathrm{A}-\mathrm{F}$ are labels referred to in the Results section.

structure mentioned in the instructions, we expect the structure of emotion-based categorizations (e.g., categorization by specific emotions, valence, or even emotional/ nonemotional) to also be quite flexible and influenced by context. More generally, the flexible nature of categorization is an issue that has not been previously addressed in the part-set cuing literature. Our study indicates that part-set cuing effects depend not only on the semantic or categorical relatedness of the stimuli, but also on which categorization scheme is most salient in that context.

There were several possible stages in the remembering process in which emotion-specific impairments may have arisen in our study. In the cue conditions of our study, participants attempted to visualize the cue picture that was represented by a word phrase, after which they saw the cue picture once again. Because participants were prompted to attempt retrieval of cue pictures, it is possible that the reduced recall seen in our paradigm is the result of retrievalinduced inhibition (Anderson, 2003) rather than an effect of strengthening associations due to simple re-presentation of cue pictures, as would follow from a competition-atretrieval explanation (Rundus, 1973). According to the competition-at-retrieval account, re-presenting some of the studied list exemplars strengthens the association between these exemplars and the superordinate category that they belong to; as a result, memory for the remaining nonstrengthened exemplars is impaired. Follow-up studies may be able to identify whether retrieval practice or re-presentation of the cued pictures is more important for obtaining the category-based impairment effects we found.

In addition, output interference effects during the final recall test may have contributed to the emotion-specific impairments, inasmuch as cue items were more likely to appear as early items in participants' recall and to inhibit subsequent recall of related items. Thus, additional research is needed to clarify which components of the reminding/remembering process are necessary to lead to emotion-specific impairments. However, regardless of which stage in the remembering process was responsible for the effects, this study provides a clear demonstration of emotion-specific impairments in memory, revealing that being reminded of an emotional event can make remembering the noncued items that elicit the same emotion less likely.

An interesting potential future direction would be to use this paradigm to reveal individual differences in the types of categories that people impose on new information. For instance, previous research suggests that older adults are more likely to focus on emotional goals when learning new information (e.g., Mather \& Carstensen, 2005; Mather \& Knight, 2005; May, Rahhal, Berry, \& Leighton, 2005). Older adults' increased emotional focus may lead to impairments in recalling same-emotion information after being reminded of an emotional event, even in contexts in which they are not oriented to notice the emotional nature of the events.

This study demonstrates that an emotion-based organization of memory can leave people vulnerable to categorybased memory phenomena along emotional lines, such as impaired memory for information that evokes the same emotion as practiced information. Furthermore, it reveals that emotional stimuli are not automatically organized in memory along emotional lines - the organization scheme used depends on what structure is most salient in that context. The finding that emotion-based memory organization only occurs when emotion is made salient has implications for other memory phenomena, such as mood-congruent memory. Our findings suggest that mood-congruent memory should be more likely to occur when people are using emotion as a way to structure information than when other categories are more salient, which may explain why mood-congruent memory effects often do not occur when moods are evoked in ways that do not call attention to emotions (Hartig et al., 1999; Hasher et al., 1985; Parrott \& Sabini, 1990).

\section{AUTHOR NOTE}

This work was supported by NIA Grant AG025340. Correspondence concerning this article should be addressed to M. Mather, Psychology Department, University of California, Santa Cruz, CA 95064 (e-mail: mather@ucsc.edu).

\section{REFERENCES}

Anderson, M. C. (2003). Rethinking interference theory: Executive control and the mechanisms of forgetting. Journal of Memory \& Language, 49, 415-445.

Barnier, A. J., Hung, L., \& Conway, M. A. (2004). Retrieval-induced forgetting of emotional and unemotional autobiographical memories. Cognition \& Emotion, 18, 457-477.

BARretT, L. F. (2006). Solving the emotion paradox: Categorization and the experience of emotion. Personality \& Social Psychology Review, 10, 20-46.

Barsalou, L. W. (1983). Ad hoc categories. Memory \& Cognition, 11, 211-227.

Barsalou, L. W. (1999). Perceptual symbol systems. Behavioral \& Brain Sciences, 22, 577-660.

Blaney, P. H. (1986). Affect and memory: A review. Psychological Bulletin, 99, 229-246.

Bower, G. H. (1981). Mood and memory. American Psychologist, 36, 129-148. 
BRown, J. (1968). Reciprocal facilitation and impairment of free recall. Psychonomic Science, 10, 41-42.

Eich, E., \& Macaulay, D. (2000). Are real moods required to reveal mood-congruent and mood-dependent memory? Psychological Science, 11, 244-248

Hartig, T., Nyberg, L., Nilsson, L. G., \& Garling, T. (1999). Testing for mood congruent recall with environmentally induced mood. Journal of Environmental Psychology, 19, 353-367.

Hasher, L., Rose, K. C., Zacks, R. T., SAnft, H., \& Doren, B. (1985). Mood, recall, and selectivity effects in normal college students. Journal of Experimental Psychology: General, 114, 104-118.

LAng, P. J., Bradley, M. M., \& Cuthbert, B. N. (1999). The international affective picture system (IAPS): Technical manual and affective ratings. Gainesville: University of Florida, Center for Research in Psychophysiology.

Mather, M., \& Carstensen, L. L. (2005). Aging and motivated cognition: The positivity effect in attention and memory. Trends in Cognitive Sciences, 9, 496-502.

Mather, M., \& Knight, M. (2005). Goal-directed memory: The role of cognitive control in older adults' emotional memory. Psychology \& Aging, 20, 554-570.

May, C. P., Rahhal, T., Berry, E. M., \& Leighton, E. A. (2005). Aging, source memory, and emotion. Psychology \& Aging, 20, 571-578.

Mikels, J. A., Fredrickson, B. L., Larkin, G. R., LindberG, C. M., Maglio, S. J., \& Reuter-Lorenz, P. A. (2005). Emotional category data on images from the International Affective Picture System. Behavior Research Methods, 37, 626-630.

NeEly, J. H., Schmidt, S. R., \& Roediger, H. L., III (1983). Inhibition from related primes in recognition memory. Journal of Experimental Psychology: Learning, Memory, \& Cognition, 9, 196-211.
Niedenthal, P. M., Halberstadt, J. B., \& Innes-Ker, A. H. (1999). Emotional response categorization. Psychological Review, 106, 337-361.

Parrott, W. G., \& SABINI, J. (1990). Mood and memory under natural conditions: Evidence for mood incongruent recall. Journal of Personality \& Social Psychology, 59, 321-336.

Peynircioǧlue, Z., \& Moro, C. (1995). Part-set cuing in incidental and implicit memory. American Journal of Psychology, 108, 1-11.

Phelps, E. A., LaBar, K. S., Anderson, A. K., O'Connor, K. J., Fulbright, R. K., \& Spencer, D. D. (1998). Specifying the contributions of the human amygdala to emotional memory: A case study. Neurocase, 4, 527-540.

RUNDUs, D. (1973). Negative effects of using list items as recall cues. Journal of Verbal Learning \& Verbal Behavior, 12, 43-50.

Schulkind, M. D., \& Woldorf, G. M. (2005). Emotional organization of autobiographical memory. Memory \& Cognition, 33, 1025-1035.

Singer, J. A., \& SAlovey, P. (1988). Mood and memory: Evaluating the network theory of affect. Clinical Psychology Review, 8, 211-251.

SlamecKa, N. J. (1968). An examination of trace storage in free recall. Journal of Experimental Psychology, 76, 504-513.

Talmi, D., LuK, B. T. C., McGarry, L. M., \& Moscovitch, M. (2007). The contribution of unrelatedness and distinctiveness to emotionallyenhanced memory. Journal of Memory \& Language, 56, 555-574.

TALMI, D., \& MoscoviTCH, M. (2004). Can semantic relatedness explain the enhancement of memory for emotional words? Memory \& Cognition, 32, 742-751.

(Manuscript received January 24, 2006; revision accepted for publication May 26, 2006.) 